\title{
Six Degrees Crankshaft Individual Air Fuel Ratio Estimation of Diesel Engines for Cylinder Balancing Purpose
}

J. Chauvin, N. Petit, P. Rouchon

École des Mines de Paris

P. Moulin, G. Corde

IFP

Copyright (C) 2006 Society of Automotive Engineers, Inc.

\begin{abstract}
In the context of modern engine control, one important variable is the individual Air Fuel Ratio (AFR) which is a good representation of the produced torque. It results from various inputs such as injected quantities, boost pressure, and the exhaust gas recirculation (EGR) rate. Further, for forthcoming $\mathrm{HCCl}$ engines and regeneration filters (Particulate filters, DeNOx), even slight AFR unbalance between the cylinders can have dramatic consequences and induce important noise, possible stall and higher emissions. Classically, in Spark Ignition engine, overall AFR is directly controlled with the injection system. In this approach, all cylinders share the same closedloop input signal based on the single $\lambda$-sensor (normalized Fuel-Air Ratio measurement, it can be rewritten with the total and air masses in the exhaust manifold as $\lambda \triangleq$ $\left.1-\frac{M_{a i r}}{M_{T}}\right)$. Ideally, all the cylinders would have the same AFR as they have the same injection set-point. Unfortunately, due to inherent flaws of the injection system (pressure waves, mechanical tolerances, ...), the total mass of fuel injected in each cylinder is very difficult to predict with a relative precision better than $7 \%$. Having a sensor in each cylinder would enable an accurate individual control. In practice, cost and reliability of multiple $\lambda$-sensors prevent them from reaching commercial products lines. In this context, individual cylinder AFR estimation can give crucial information to get the $\mathrm{HCCl}$ running better.
\end{abstract}

The contribution of this paper is the design and experimental tests of a real-time observer for the individual cylinder AFR using the reliable and available $\lambda$-sensor placed downstream the turbine as only measurement. In previous works, the methods used to reconstruct the AFR of each cylinder from the UEGO (Universal Exhaust Gas Oxygen) $\lambda$-sensor measurement are based on the permutation dynamics at the TDC (Top-Dead Center) time-scale and a gain identification technique. Here, we propose a higher frequency approach (6 degree crankshaft angle modelling and update instead of 180(TDC)). We design an observer on the balance model of the exhaust and design a high frequency observer to solve the problem. We use a physics-based model underlying the role of periodic input flows (gas flows from the cylinders into the exhaust manifold). The observer is validated experimentally on a 4 cylinder $\mathrm{HCCl}$ engine. As a conclusion, we provide results of closed-loop control using the proposed technique to prove the relevance of this approach.

\section{INTRODUCTION}

Performance and environmental requirements has imposed a sophistication of control strategies over the last thirty years. Model based control and engineering breakthroughs were the keys to take advantage of advanced combustion engine. The focus moved to considerably lower time scale reaching the combustion level which appears as the ultimate goal $[1,2]$. Originally considering cycle to cycle measurements, the light is now on $6^{\circ}$ degree crank angle measurements. One would use direct measurement of combustion pressures. Unfortunately, this would require expensive sensors, and imply restrictions on engine design. Thus, an already existing sensor is preferred. It measures the angular position of the crankshaft and is used to infer the instantaneous engine speed. With that sensor, several tentative solutions for combustion torque control and estimation have been designed (see for example [3, 4, 5, 6, 7]).

An other important step toward the combustion control is the Air Fuel Ratio (AFR) control and estimation. It results from various inputs such as injected quantities, exhaust gas recirculation (EGR) rate and boost pressure. Classically, in Spark Ignition engine, overall AFR is directly 
controlled with the injection system. In this approach, all cylinders share the same closed-loop input signal based on the single $\lambda$-sensor (normalized Fuel-Air Ratio measurement, it can be rewritten with the total and air masses in the exhaust manifold as $\left.\lambda \triangleq 1-\frac{M_{a i r}}{M_{T}}\right)$. Ideally, all the cylinders would have the same AFR as they have the same injection set-point. Unfortunately, due to inherent flaws of the injection system (pressure waves, mechanical tolerances, ...), the total mass of fuel injected in each cylinder is very difficult to predict with a relative precision below $7 \%$. This unbalance induces important noise, possible stall and higher emissions. For forthcoming Homogeneous Charge Compression Ignition $(\mathrm{HCCl})$ engines (see $[8,9,10,11]$ for an overview of the technology issues) and regeneration filters (Particulate filters, $\mathrm{DeNO}_{x}$ ) (see $[12,13,14]$ for example), even slight unbalance between the cylinders can have dramatic consequences and induce important noise, possible stall and higher emissions. Individual cylinder control is needed. In this context, individual cylinder AFR estimation can give crucial information to get the $\mathrm{HCCl}$ running better.

The contribution of this paper is the design of a real-time observer for the individual cylinder AFR using the reliable and available $\lambda$-sensor placed downstream the turbine as only measurement and its use for control purpose. In previous work, individual cylinder control has been addressed using individual cylinder $\lambda$-sensor in [15]. In practice, cost and reliability of multiple $\lambda$-sensors prevent them from reaching commercial products lines. With a single $\lambda$-sensor, (see $[16,17,18])$ the methods used to reconstruct the AFR of each cylinder are based on the permutation dynamics at the TDC (Top-Dead Center) time-scale and a gain identification technique. We propose here a higher frequency approach ( $6^{\circ}$ sample angle instead of $90^{\circ}$ (TDC)) by designing a nonlinear observer on the balance model of the exhaust. The physics-based model stresses the role of periodic input flows (gas flows from the cylinders into the exhaust manifold). The nonlinear observer is designed and validated experimentally (on a four cylinder turbocharged diesel test bench presented in [19]). Eventually, we use it for control purposes.

The paper is organized as follows. In Section 2, we present the exhaust modelling and the cylinder individual AFR model. In Section 3, we propose a nonlinear cylinder individual AFR observer. The simulator and simulation results are presented in Section 4 and 5 respectively. Implementation issues are investigated in Section 6. Experimental results and AFR balancing control are presented in Section 7 and 8 respectively. Future directions are given in Section 9.

\section{NOMENCLATURE}

\section{EXHAUST MODELLING}

Figure 1 shows the flow sheet of individual AFR from the cylinders outlet down to the turbine. From the cylinders to the $\lambda$-sensor (located downstream the turbine), the gases
Table 1: Nomenclature. e. m. refers to the exhaust manifold

\begin{tabular}{|c|c|c|}
\hline Symb. & Quantity & Unit \\
\hline$\alpha$ & Crankshaft angle & rad \\
\hline$M_{T}$ & Total mass of gas in the e. $\mathrm{m}$. & $\mathrm{kg}$ \\
\hline$M_{a i r}$ & Mass of air in the e. $\mathrm{m}$. & $\mathrm{kg}$ \\
\hline$N_{e}$ & Engine Speed & rpm \\
\hline$d_{T}$ & Gas flow rate through the e. $\mathrm{m}$. & $\mathrm{kg} / \mathrm{s}$ \\
\hline$d_{i}$ & Gas flow rate from cylinder $i$ & $\mathrm{~kg} / \mathrm{s}$ \\
\hline$\Xi$ & Operating conditions & \\
\hline$D_{a s p}$ & Mean aspirated flow & $\mathrm{kg} / \mathrm{s}$ \\
\hline$T_{e x h}$ & Temperature in the e. $\mathrm{m}$. & $\mathrm{K}$ \\
\hline$N_{\text {turbo }}$ & Turbocharger speed & rpm \\
\hline$\lambda_{i}$ & $\begin{array}{l}\text { Normalized Fuel-Air Ratio in the } \\
\text { exhaust pipe of cylinder } i\end{array}$ & \\
\hline$\lambda$ & $\begin{array}{l}\text { Normalized Fuel-Air Ratio } \\
\text { measurement }\end{array}$ & \\
\hline$P$ & Pressure in the e. $\mathrm{m}$. & bar \\
\hline$z_{0}$ & $\begin{array}{l}\text { Total mass in the e. } \mathrm{m} \text {. } \\
\text { under atmospherical conditions }\end{array}$ & $\mathrm{kg}$ \\
\hline$n_{c y l}$ & Number of cylinders & \\
\hline$\Delta \alpha \triangleq \frac{\pi}{30}$ & Angular sample time & $\mathrm{rad}$ \\
\hline$\delta \triangleq \frac{\Delta \alpha}{N_{e}}$ & Constant & $\mathrm{rad} / \mathrm{rpm}$ \\
\hline$\gamma_{T}, \gamma^{\gamma_{e}}$ & Constants & \\
\hline
\end{tabular}

travel through the exhaust pipes, the exhaust manifold, and the turbocharger. All these components have an influence on the gas pressure, temperature, and composition in the exhaust manifold. In a very naive model, the gases move at constant speed, without mixing. In practice, diffusion and mixing effects are present. We propose a nonlinear model to take these into account. Our approach focuses on macroscopic balances involving experimentally derived nonlinear functions.

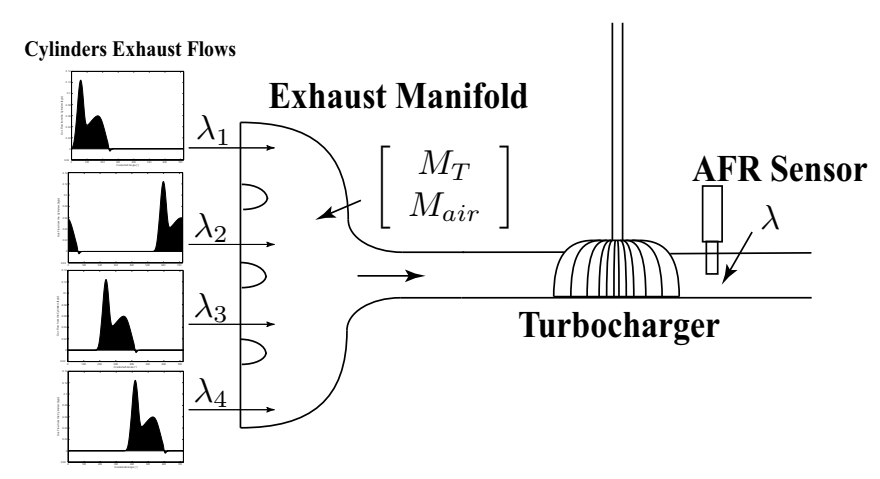

Figure 1: Exhaust dynamics: Individual Air-Fuel Ratio problem.

MASS BALANCE IN THE EXHAUST MANIFOLD Notations are given in Table 1. Balance equations (1) and (2) 
and fixed operating conditions (3) yield

$$
\begin{aligned}
\frac{d M_{T}}{d \alpha} & =f_{1, \Xi}\left(M_{T}, \alpha\right) \\
\frac{d M_{a i r}}{d \alpha} & =f_{2, \Xi}\left(M_{T}, M_{a i r},\left\{\lambda_{i}\right\}_{i \in\left[1, n_{c y l}\right]}, \alpha\right) \\
\frac{d \lambda_{i}}{d \alpha} & =0, \quad \forall i \in\left[1, n_{c y l}\right]
\end{aligned}
$$

where

$$
f_{1, \Xi}\left(M_{T}, \alpha\right)=-\frac{1}{N_{e}} d_{T}\left(M_{T}, \Xi\right)+\frac{1}{N_{e}} \sum_{i=1}^{n_{c y l}} d_{i}(\alpha, \Xi)
$$

and

$$
\begin{aligned}
& f_{2, \Xi}\left(M_{T}, M_{a i r},\left\{\lambda_{i}\right\}_{i \in\left[1, n_{c y l}\right]}, \alpha\right)= \\
& \quad-\frac{1}{N_{e}} \frac{M_{a i r}}{M_{T}} d_{T}\left(M_{T}, \Xi\right)+\frac{1}{N_{e}} \sum_{i=1}^{n_{c y l}}\left(1-\lambda_{i}\right) d_{i}(\alpha, \Xi)
\end{aligned}
$$

Operating conditions are defined by the $\Xi$ parameters (mean aspirated flow $D_{a s p}$, exhaust temperature $T_{e x h}$, turbocharger speed $N_{\text {turbo }}$ ). They are assumed constant over an engine cycle.

The $T_{0}$-periodic $d_{i}(., \Xi)$ functions are modelled through interpolation of a large number of available data. The functions family $\left\{d_{i}\right\}_{i=1 \ldots n_{c y l}}$ is a linearly independent family of the set of continuous $T_{0}$-periodic functions.

The flow rate $d_{T}$ comes out of the exhaust manifold. It is a function of the total mass $M_{T}$, smooth away from 0 , and can be factorized as

$$
d_{T}\left(M_{T}, \Xi\right)=p\left(M_{T}, \Xi\right) M_{T}
$$

with for a given operating condition $\Xi, p$ a positive increasing (concave) function with respect to the total mass $M_{T}$, e.g. $p(z, \Xi)=p_{0}(\Xi) \sqrt{2 \frac{\gamma}{\gamma-1}\left(\left(\frac{z}{z_{0}}\right)^{-\frac{2}{\gamma}}-\left(\frac{z}{z_{0}}\right)^{-\frac{\gamma+1}{\gamma}}\right)}$. Usually given by a 2D look-up table, the flow rate is modelled as a flow through a restriction [20] with a variable section depending on the pressure ratio and the turbocharger speed (as proposed in [21] and [22]). Composition of the flow through the turbine and in the exhaust manifold are equal.

MEASUREMENTS At first, two sensors are considered for our observer design, although extra sensors are available on a prototype engine for sake of performance analysis. The measurements are

- $P$ the pressure in the exhaust manifold assumed to be related to the total mass by $P=\gamma_{T} M_{T}$. In this work, the exhaust pressure sensor is eventually substituted with an open loop model. The reason of this choice is to propose a versatile observer, able to work with or without an exhaust pressure sensor usually not available on commercial engine.

- $\lambda$ the normalized Fuel-Air Ratio measurement. It can be rewritten without with the total and air masses in the exhaust manifold as $\lambda \triangleq 1-\frac{M_{a i r}}{M_{T}}$
REFERENCE

\section{SYSTEM Let}

$x$ $\left[\begin{array}{lllll}M_{T} & M_{a i r} & \lambda_{1} & \ldots & \lambda_{n_{c y l}}\end{array}\right]^{T} \in \mathbb{R}^{n_{c y l}+2}$ be the state and $y=\left[\begin{array}{ll}P & \lambda\end{array}\right]^{T} \in \mathbb{R}^{2}$ the measurements. Following (1)-(2)-(3), the reference system reads

$$
\left\{\begin{aligned}
\frac{d x_{1}}{d \alpha} & =f_{1, \Xi}\left(x_{1}, \alpha\right) \\
\frac{d x_{2}}{d \alpha} & =f_{2, \Xi}\left(x_{1}, x_{2}, \hat{x}_{2+i}, \alpha\right) \\
\frac{d x_{2+i}}{d \alpha} & =0, \forall i \in\left[1, n_{c y l}\right] \\
y_{1} & =\gamma_{T} x_{1} \\
y_{2} & =1-\frac{x_{2}}{x_{1}}
\end{aligned}\right.
$$

\section{NONLINEAR INDIVIDUAL CYLINDER AFR OBSERVER}

We consider the following time-varying observer

$$
\left\{\begin{aligned}
\frac{d \hat{x}_{1}}{d \alpha}= & f_{1}\left(\frac{1}{\gamma_{T}} y_{1}, \alpha\right)+\frac{L_{1}}{N_{e}}\left(\frac{y_{1}}{\gamma_{T}}-\hat{x}_{1}\right) \\
\frac{d x_{2}}{d \alpha}= & f_{2}\left(\frac{1}{\gamma_{T}} y_{1},\left(1-y_{2}\right) \frac{1}{\gamma_{T}} y_{1}, \hat{x}_{2+i}, \alpha\right) \\
& +\frac{L_{2}}{N_{e}}\left(\left(1-y_{2}\right) \frac{1}{\gamma_{T}} y_{1}-\hat{x}_{2}\right) \\
\frac{d \hat{x}_{2+i}}{d \alpha}= & -\frac{L_{\lambda}}{N_{e}} d_{i}(\alpha)\left(\left(1-y_{2}\right) \frac{1}{\gamma_{T}} y_{1}-\hat{x}_{2}\right)
\end{aligned}\right.
$$

where the last equations hold for all $i=1, \ldots, n_{c y l}$, and where $L_{1}, L_{2}$, and $L_{\lambda}$ are positive constants. Convergence of the observer rate $\hat{x}$, described by System (5), to the state $x$ of the reference (1)-(2)-(3) is proven in [23] by exhibiting a Lyapunov function and using LaSalle's theorem [24] to conclude to the convergence of the observer.

\section{SIMULATOR}

ENGINE MODELLING APPROACH Mainly three types of modelling levels are used for engine simulation. The most accurate modelling approach is the Computational Fluid Dynamics (CFD) 2D/3D simulation. It is dedicated to studying combustion chamber and permits to finely capture local phenomena in the cylinder such as turbulent combustion and chemical kinetics. The characteristic timescale of CFD simulation is to the order of the turbulent timescale. At the present time, the CPU requirements of such a simulation only allows to run a few engine cycles. The simplest modelling approach consists in representing the engine with operating condition look-up tables. This level lowers CPU load below real time and is used in connection with the whole powertrain model and to simulate standard driving cycles of a vehicle. The characteristic timescale of vehicle simulation is approximately of 0.1 second. At a turning point between these two approaches, the third modelling level is the "engine system modelling". This approach involves phenomenological or empirical models and allows to represent the complete engine with a characteristic timescale approximately of 0.1 crankshaft degree. Thanks to dedicated code optimization to alleviate the CPU load, the engine system model allows to accurately reproduce the behavior of the engine during transient such as driving cycle while reaching the real time in certain conditions. Therefore, this approach 
is especially adapted to be used as a support tool for engine control design from the control development to the hardware-in-the-loop validation [25].

IFP-ENGINE LIBRARY The engine system simulation tool used for this study is the IFP-ENGINE library. It has been developed in the IMAGINE's numerical platform AMESim which is a numerical environment for modelling and simulation of dynamic systems inspired by Bond Graph approach. The numerical solver automatically and dynamically selects the best-suited calculation method among 17 available algorithms. Gas under consideration consist of 3 species : fresh air, vaporised fuel and burnt gas. Two phenomenological efficient models are available to represent gasoline [26] and Diesel combustion [27].

HPC DIESEL ENGINE MODEL The goal of engine system simulation is to supply the relevant model for the specific application. User expectations have to be accurately understood in order to achieve the optimum trade-off between physical description and calculation times. Engine control design has strong time constraints. It needs to consider a large amount of engine operating points and is oriented towards real time environment. This model is running with a CPU time less than 20 times the real time with a variable time step solver on a $3 \mathrm{GHz}$ PC. Fixed time step solvers can be used to reduce the CPU time, especially to build the real time engine model. Air path includes a compressor, pipes, a heat exchanger, a throttle and an intake manifold. All these elements are represented by dedicated submodels. The compromise to be done between the engine model accuracy and the simulation time cost has a major impact on the complexity of the phenomena taken into account in this part of the engine model. High frequency pulses modelling in the intake manifold can be heavily time consuming. A trade-off between accuracy of instantaneous pressure fluctuations and time consumption is to be found. This is done by comparing different levels of manifold modelling details. For our purpose, the best compromise is the approach yielding the lowest time consumption while limiting the effect of in-manifold phenomena neglection on neighboring elements. The combustion chamber is connected to the air path through the cylinder head which acts thanks to valve lift laws and permeability behavior model derived from experimental characterization. The fuel injection system allows to perform up to three injections per cycle that are controlled with the common rail pressure by means of injection starting time and duration. Cylinder wall heat losses are modelled using a Woschni's approach with three independent temperatures for the cylinder head, the piston and the liner. The combustion heat release model is based on the conventional OD Diesel combustion model approaches [28, 29] extended to multi-pulse injection, auto-ignition delay and EGR effect correction in order to get good combustion behavior in the whole range of operating set points, especially in both Highly Premixed Combustion (HPC) and conventional combustion modes.

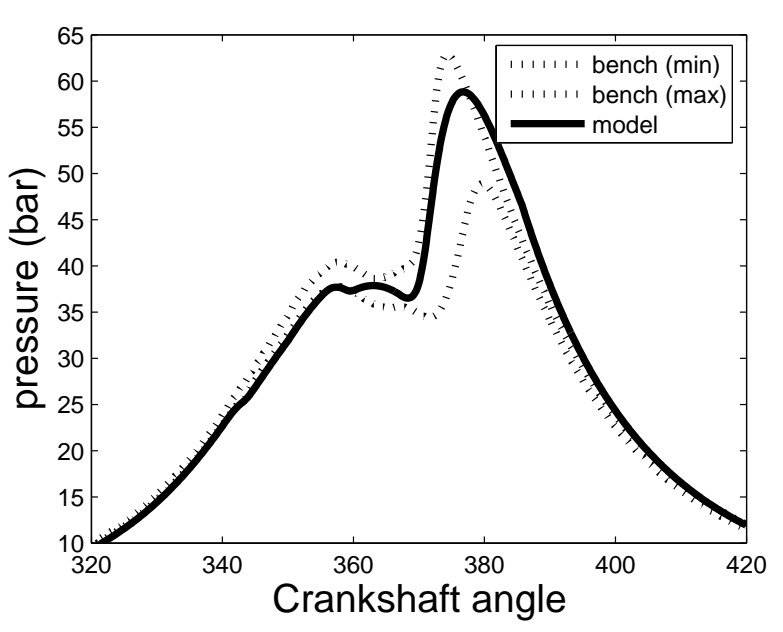

Figure 2: Model/Bench cylinder pressure comparison at $\mathrm{IMEP}=6$ bar $(\mathrm{EGR}=35 \%)$.

A typical result is reported in Figure 2 (see [19] for more details). This model is a good representation of the main phenomena of the engine and is an appropriate tool for control purposes.

\section{SIMULATION RESULTS}

TESTS SETUP The estimator described above is tested both on the simulator presented above and the testbench. On both simulation and experimental testbed, we apply an injection duration timing trajectory to introduce unbalance. It produces offsets in injection which lead to AFR disturbances. More precisely the injection steps have an effect on the average level of the measured AFR and introduce oscillations of the overall AFR signal. These oscillations are the direct consequences of the individual AFR difference. During cylinder 1 exhaust phase, the AFR increases in the manifold, and then decreases while the other cylinders exhaust phases occur. The magnitude of the oscillations is related to the amount of the AFR difference between the cylinders and the gas mass in the manifold (and thus to its volume). The oscillation is then propagated to the turbine, and to the UEGO sensor, where it is filtered. This is the information that we exploit in the nonlinear observer (5).

SIMULATION RESULTS AND COMMENTS Figures 3 presents results from simulation. The results are both quantitatively and qualitatively accurate. We reproduce well the evolution of the AFR. In practice, numerical convergence is achieved within 4 engine cycles.

\section{FROM SIMULATION TO EXPERIMENTATION}

On the test bench, we use the nonlinear observer according to the scheme in Figure 4. Several practical is- 

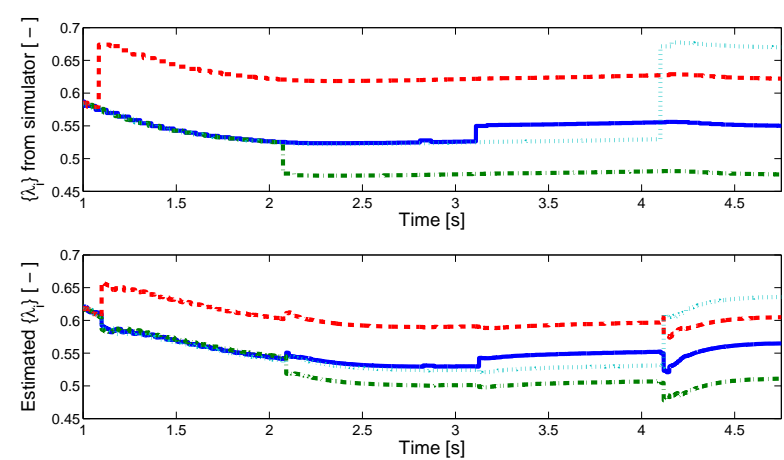

Figure 3: FAR trajectory on simulation at $2000 \mathrm{rpm}$. Top: Reference values from simulation. Bottom: Reconstructed with (5).

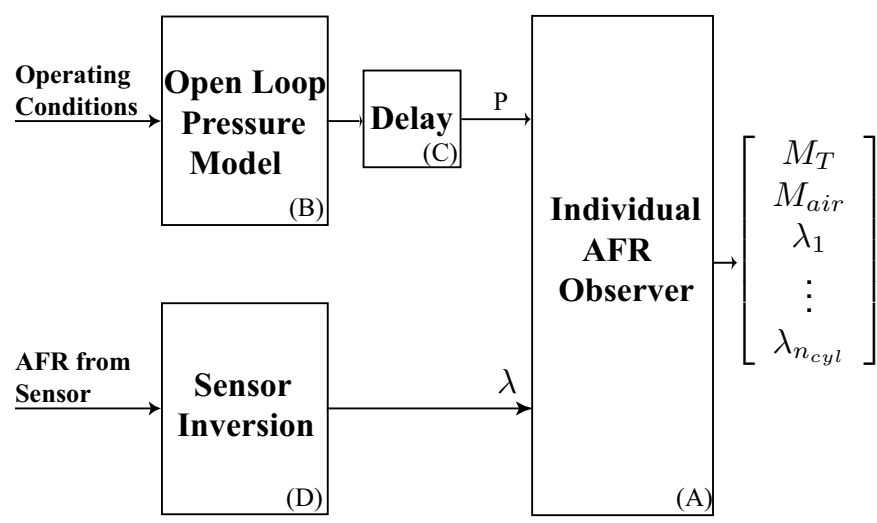

Figure 4: Observer Scheme as used in the test bench.

sues need to be considered. We now detail these.

OBSERVER IMPLEMENTATION Block $(\mathrm{A})$ is the implementation of estimator (5). An explicit Euler approximation is used. Parameters are experimentally tuned.

OPEN LOOP PRESSURE MODEL Exhaust pressure sensor can be expected for forthcoming $\mathrm{HCCl}$ vehicles only. In experimentation, we consider not having this sensor and give to the estimator an open loop value. This value is given by the open loop balance with the input flows $\left(d_{i}\right)$ and output flow $d_{T}$ as described previously. This model is implemented in Block (B) in Figure 4.

GAS TRANSPORT DELAY Lags due to gas transport along the engine exhaust (pipes and dead volumes), and the dead time of the sensor are not represented by the model described above in System (1)-(2)-(3). Delays can be lumped into a single delay for the complete exhaust system, and the model can be inverted. This delay can be identified and kept as a constant for a given setpoint on the (engine speed, load) map. This estimation is implemented in Block (C) in Figure 4.
AFR SENSOR INVERSION The AFR sensor has a lowpass transfer function. Sampling noise is filtered by a very high frequency low-pass filter. The sensor dynamics can be approximated by a second order filter. In order to robustly invert dynamics of the sensor, we apply an observer based on an adaptive Fourier decomposition as described in [30] (Block (D) in Figure 4).

\section{EXPERIMENTAL RESULTS}

We applied the same injection duration timing trajectories at the test bench. The test bench used for validation is a 4 cylinders $\mathrm{DI}$ engine with a Variable Geometry Turbocharger (VGT). Results are reported in Figures 5 and 6. These represent the nonlinear estimation of the individual cylinder AFR about two engine setpoints. The same tuning parameters are kept from simulation to experimentation.
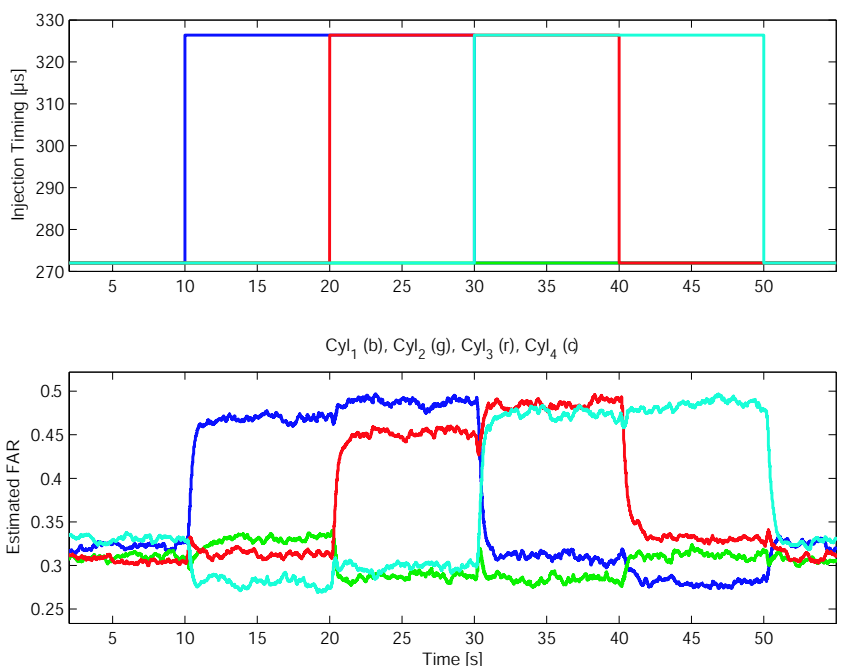

Figure 5: Test bench (2000 rpm and 3 bar). Top: Injection Duration Offsets. Bottom: Individual Estimated AFR.

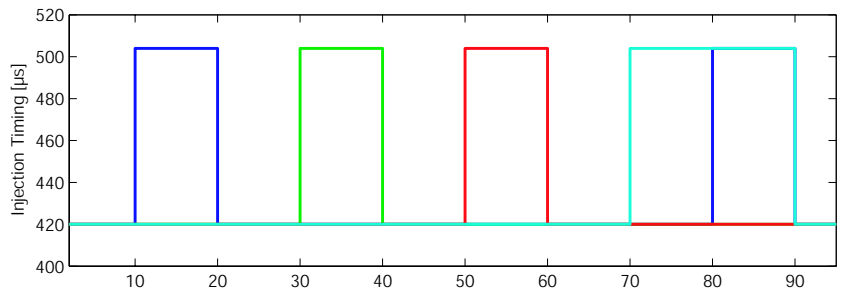

$\mathrm{Cyl}_{1}(\mathrm{~b}), \mathrm{Cyl}_{2}(\mathrm{~g}), \mathrm{Cyl}_{3}(\mathrm{r}), \mathrm{Cyl}_{4}$ (c)

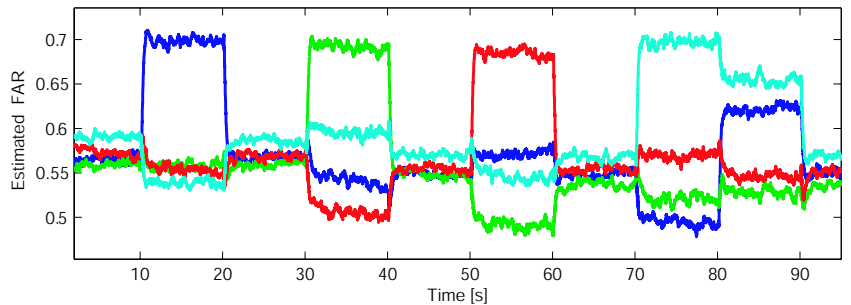

Figure 6: Test bench (2500 rpm and 9 bar). Top: Injection Duration Offsets. Bottom: Individual Estimated AFR.

Further, in all test bench cases, we are able to predict the individual cylinder AFR well. Further, we can easily detect the AFR unbalance and have a good estimation of 
the peaks of the AFR disturbances, the magnitude of the individual AFR offsets are satisfactory. As it appears in Figures 5 and 6 , a diagnosis can be derived from the values estimated by the individual AFR observer (5). Offsets in injection duration are strongly correlated to the offset of AFR.

\section{TOWARDS AFR BALANCING}

Having at our disposal an estimator of the individual AFR, simple issues such as control of AFR imbalance between the cylinders can be addressed by controlling the individual injection quantities (which is the relevant control strategy for such unbalance) with a PI controller. Figure 7 presents the results of such a control strategy relying on the individual AFR estimation. On the testbench, we turn off the control at $7.5 \mathrm{~s}$ which leads to the natural imbalance of the engine. We introduce an injection offset on cylinder 2 at $19 \mathrm{~s}$ and finally turn the controller back on at $36 \mathrm{~s}$. Figure 8 presents the results of such a control strategy relying on the individual AFR estimation on another engine point. We see that the control is efficient and that we are able to balance the torque produced by each cylinder.

\section{CONCLUSIONS AND FUTURE DIRECTIONS}

The work presented in this paper reports the development and implementation of an individual cylinder AFR estimator. It reconstructs the AFR of each cylinder from a measurement made by a single sensor located downstream the turbine. The availability of such an estimator giving reliable information can lead to improvements on diesel engines in terms of combustion control, noise, and pollutant emissions. This information will be used to control the unbalance between the cylinders. Indeed by controlling the individual injection quantity (which is the relevant control for such unbalance observation) a simple PI controller will lead to the balance of the individual AFR. In the context of combustion real-time control, this observer is a handy tool. It could be used in a closed loop controller of the fuel injectors. This is the long term goal of our work. Moreover, this observer is easily transposed to various engine speeds and loads. Its dynamics are expressed in angular time scale and do not require any model for the combustion process. Theoretically, the gains do not need to be updated when the set-point is changed. However we need to integrate the exhaust gas recirculation flow (EGR) for the $\mathrm{HCCl}$ studies. We are currently investigating this point in an exhaustive test campaign on the test bench.

Acknowledgments: The authors are thankful Jérôme Vauchel for his high contribution on the experimental work.

\section{References}

[1] L. Guzzella and A. Amstutz. Control of Diesel engines. Proc. of the IEEE Control Systems Magazine, 18:53-71, 1998.
[2] U. Kiencke and L. Nielsen. Automotive Control Systems For Engine, Driveline, and Vehicle. SAE Internationnal, 2000.

[3] G. Rizzoni. Estimate of indicated torque from crankshaft speed fluctuations: A model for the dynamics of the IC engine. Proc. of the IEEE Transactions on Vehicular Technology, 38:169-179, 1989.

[4] P. Gyan, S. Ginoux, J.C. Champoussin, and Y. Guezennec. Crankangle based torque estimation: Mechanistic/stochastic. In Proc. of the SAE Conference, 2000.

[5] Y. Guezennec and P. Gyan. A novel approach to realtime estimation of the individual cylinder pressure for S.I. engine control. In Proc. of the SAE Conference, 1999.

[6] J. Chauvin, G. Corde, P. Moulin, M. Castagné, N. Petit, and P. Rouchon. Real-time combustion torque estimation on a Diesel engine test bench using timevarying Kalman filtering. In Proc. of the the 43rd IEEE Conf. Decision and Control, 2004.

[7] J. Chauvin, G. Corde, P. Moulin, M. Castagné, N. Petit, and P. Rouchon. Real-time combustion torque estimation on a Diesel engine test bench using an adaptive Fourier basis decomposition. In Proc. of the the 43rd IEEE Conf. Decision and Control, 2004.

[8] J. Kahrstedt, K. Behnk, A. Sommer, and T. Wormbs. Combustion processes to meet future emission standards. In Motortechnische Zeitschrift, pages 14171423, 2003.

[9] A. Hultqvist, U. Engdar, B. Johansson, and J. Klingmann. Reacting boundary layers in a homogeneous charge compression ignition $(\mathrm{HCCl})$ engine. In Proc. of the SAE Conference, number 2001-011032, 2001.

[10] P. Amnéus, D. Nilsson, F. Mauss, M. Christensen, and B. Johansson. Homogeneous Charge Compression Ignition engine: Experiments and detailed kinetic calculations. In $4^{\text {th }}$ International Symposium on Diagnostic and Modeling in Internal Combustion Engines, 1998.

[11] B. Walter and B. Gatellier. Near zero $\mathrm{NO}_{x}$ emissions and high fuel efficiency diesel engine: the $\mathrm{NADI}^{T M}$ concept using dual mode combustion. 58(1):101114, 2003.

[12] P. Moraal, Y. Yacoub, U. Christen, B. Carberry, and Guérin S. Diesel particulate filter regeneration: Control or calibration? In IFAC Symp. Advances in Automotive Control (AAC04), 2004.

[13] T. Auckenthaler, C. Onder, and H. Geering. Aspects of dynamic three-way catalyst behaviour including oxygen storage. In IFAC Symp. Advances in Automotive Control (AAC04), 2004. 


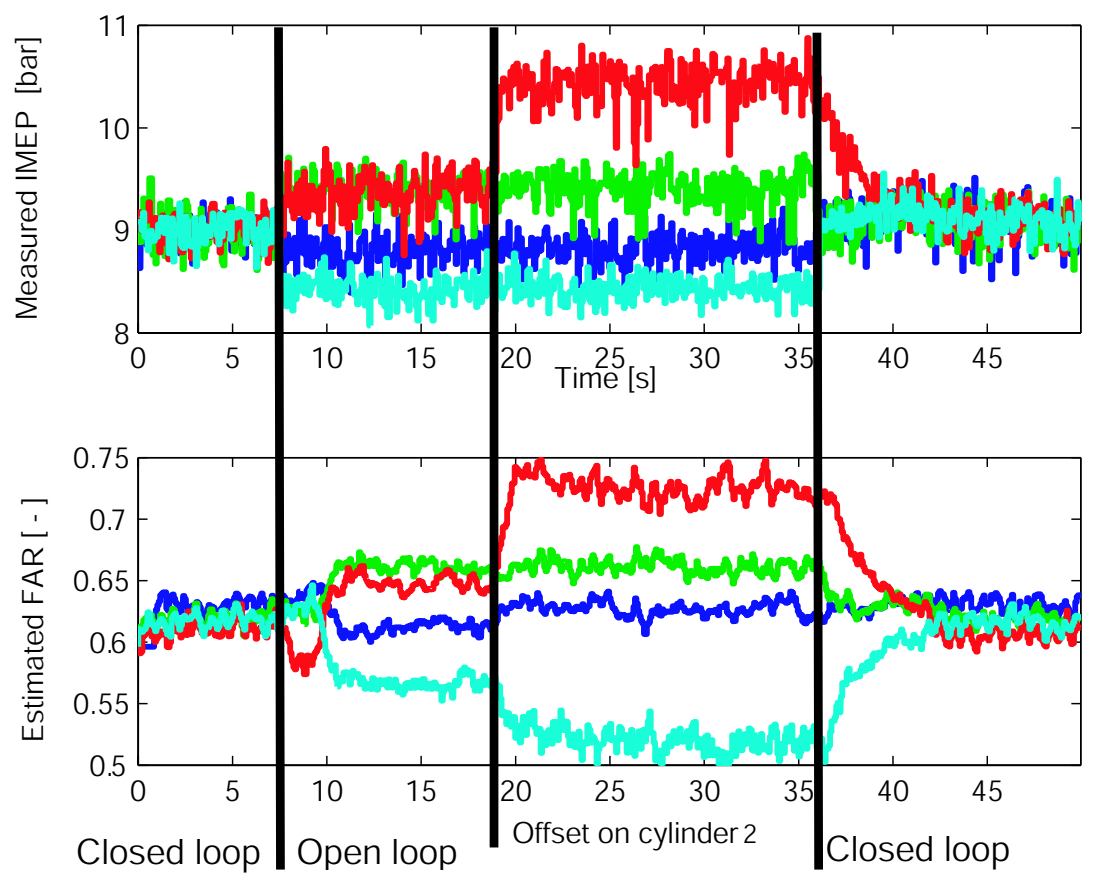

Figure 7: Torque balancing based on individual AFR estimation: test bench results (Engine Speed 1500rpm, IMEP 9bar). We turn off the control at $7.5 \mathrm{~s}$, we introduce an injection offset on cylinder 2 at $19 \mathrm{~s}$ and finally turn the controller back on at 36s. Top: IMEP from cylinder pressure sensors. Bottom: Individual Estimated AFR with the nonlinear observer.

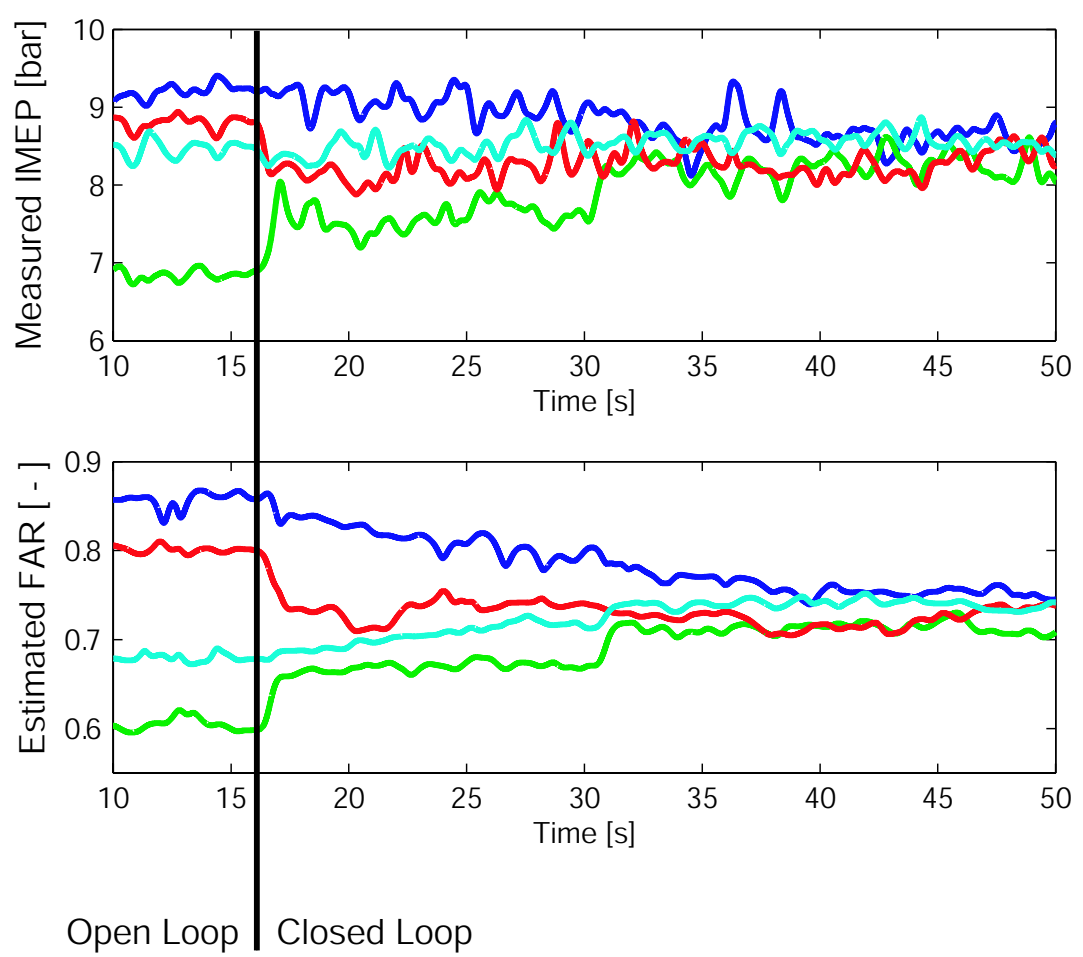

Figure 8: Torque balancing based on individual AFR estimation: test bench results (Engine Speed 2250rpm, IMEP 8bar). We turn on the control at $16 \mathrm{~s}$. Bottom: Individual Estimated AFR with the nonlinear observer. 
[14] T. Kreuzer, E. Lox, D. Lindner, and Leyrer J. Advanced exhaust gas aftertreatment systems for gasoline and Diesel fuelled vehicles. Catalysis Today, 29:17-27, 1996.

[15] P. Berggren and A. Perkovic. Cylinder individual lambda feedback control in an SI engine. Master's thesis, Linköpings Universitet, 1996.

[16] J. Grizzle, K. Dobbins, and J. Cook. Individual cylinder air-fuel ratio control with a single EGO sensor. Proc. of the IEEE Transactions on Vehicular Technology, 40(1):357-381, February 1991.

[17] C. Carnevale and M. Hadji. Cylinder to cylinder AFR control with an asymmetrical exhaust manifold in a GDI system. In Proc. of the SAE Conference, number 981064, 1998.

[18] J. Fantini and J.-F. Burq. Exhaust-intake manifold model for estimation of individual cylinder air fuel ratio and diagnostic of sensor-injector. In Proc. of the SAE Conference, number 2003-01-1059, 2003.

[19] A. Albrecht, J. Chauvin, S. Potteau, and G. Corde. Design of real-time torque balancing control for highly premixed combustion engine using a 1d Diesel engine model. In Proc. of the IAV Conference "Engine process simulation and supercharging", 2005.

[20] J. Heywood. Internal Combustion Engine Fundamentals. McGraw-Hill, Inc, 1988.

[21] J. Jensen, A. Kristensen, S. Sorensen, N. Houbak, and $\mathrm{E}$. Hendricks. Mean value modeling of a small turbocharged Diesel engine. In Proc. of the SAE Conference, number 910070, 1991.

[22] P. Moraal and I. Kolmanovsky. Turbocharger modeling for automotive control applications. In Proc. of the SAE Conference, number 1999-01-0908, 1999.

[23] J. Chauvin, P. Moulin, G. Corde, N. Petit, and P. Rouchon. Real-time nonlinear individual cylinder Air Fuel Ratio observer on a Diesel engine test bench. In Proc. of the IFAC World Congress, 2005.

[24] H. Khalil. Nonlinear Systems. Prentice-Hall, Inc., 1992.

[25] A. Albrecht, G. Corde, and V. Knop. 1d simulation of turbocharged gasoline direct injection engine for transient strategy optimization. In Proc. of the SAE Conference, number 2005-01-0693, 2005.

[26] F. Lafossas, O. Colin, F. Le Berr, and P. Ménégazzi. Application of a new 1d combustion model to gasoline transient engine operation. In Proc. of the SAE Conference, number 2005-01-2107, 2005.

[27] T. Jaine, A. Benkenida, P. Ménégazzi, and P. Higelin. Zero dimensional computation of diesel spray - comparison with experiments and $3 d$ model. In $6^{\text {th }}$ International Conference on Engines for Automobile, Capri, Italy, 2003.
[28] F. Chmela and G. Orthaber. Rate of heat release prediction for direct injection Diesel engines based on purely mixing controlled combustion. In Proc. of the SAE Conference, number 1999-01-0186, 1999.

[29] C. Barba and C. Burkhardt. A phenomenological combustion model for heat release rate prediction in high-speed DI Diesel engines with common rail injection. In Proc. of the SAE Conference, number 200001-2933, 2000.

[30] J. Chauvin, , G. Corde, N. Petit, and P. Rouchon. Periodic input observer design: Application for unbalance diagnosis. In Proc. of the SAE Conference, number 2006-01-0181, 2006. 